\title{
Investigation of the Mechanical Properties of Palm Kernel Fiber Reinforced with Waste Water Sachet (Polyethylene) Composite Material
}

\section{Obiukwu Osita ${ }^{1, a,{ }^{*}}$, Alo Francis ${ }^{2}$, Onukwube Christogonus ${ }^{1}$, Onwukwe Ejike ${ }^{1}$}

${ }^{1}$ Department of Mechanical Engineering, School Of Engineering and Engineering Technology, Federal University of Technology, Owerri, Imo State, Nigeria

${ }^{2}$ Department of Materials and Metallurgical, Engineering Department, Obafemi Awolowo University, Ife, Nigeria

a*obiukwu@futo.edu.ng

Keywords: palm kernel fibre, waste water sachet (polyethylene), tensile, impact and hardness test.

\begin{abstract}
An investigation was carried out to produce a composite material of palm kernel fibre and empty water sachet (polyethylene). The percentage composition of the fibre was varied likewise the matrix the reinforcing material was varied from $5 \mathrm{wt} . \%$ to $20 \mathrm{wt}$. \%. The materials were heated and poured in a mould. Mechanical properties of the composites were tested and determined. Impact strength of the materials gave prime information on possible application of the developed material. After the analysis, it was verified that tensile strength decreased with filler loading and the material with $10 \mathrm{wt}$. \% of palm kernel fibre developed a better mechanical property following its high tensile strength and impact strength and thus material will be most useful where strength to weight ratio is needed.
\end{abstract}

\section{Introduction}

The disposal of solid wastes such as water sachet and palm kernel fibre into our environment is a serious issue that needed to be addressed and a remedy to it proffered. Palm kernel fibre is a waste gotten from the extraction of palm oil from the kernel disposed after the content is used. These two wastes possess a great environmental degradation that usually results in pollutions, blocking of water channels and in most cases to outbreak of disease. According to [2], in developing country like Nigeria, sachet water cannot be easily substituted by table water for drinking purposes, as the table water cost more than five times that of sachet water. Sachet water has become popular in almost all the communities but unfortunately, this has led to a new source of solid waste since the LDPE has extremely low rate of degradation [3], [4].

Many works have been devoted to the use of other natural fillers in composite in recent past and palm kernel waste is a potential candidate for the development of new composite because of their high strength and modulus properties [5-7]. A number of investigations have been carried out to assess the potentials of palm kernel fibre reinforced polymer composite in the automotive and other industries owning to its physical and mechanical properties [8-10]. This paper aims to development of new composite material from waste water sachet (pure water sachet) and palm kernel waste from our surroundings and to determine mechanical properties of the developed composite material. Huda et al. [11], Clemons and Sanadi [12] studied the effects of fibre content, coupling agent and temperature on the impact performance of kernel fibre reinforced polyethylene. Earlier studies by Singh [13], Dhib and Al-Nidawy [14], Ashby [15], Bledzki Gassan [16], Amoako et al. [17], Samotu et al. [18], Abdullah et al. [19], and Acha et al. [20] proved that palm kernel fibre, waste water sachet can be used as effective reinforcement and bonded in Polyethylene matrix.

\section{Materials and Method}

The palm kernel fibres were gathered locally and were washed with detergent to remove left over of oil on it. Then it was sun dried for three days and in an oven at the temperature of $150{ }^{\circ} \mathrm{C}$ degrees. The grinding of the palm kernel was done using Grinder/polisher machine Model 900, (maker south bay technology). The separation process of the raw particle fibres was done using round 
vibratory sieves (Unit Test) for different sizes of sieves, namely $1.18 \mathrm{~mm}, 600 \mu \mathrm{m}, 400 \mu \mathrm{m}, 300 \mu \mathrm{m}$, $200 \mu \mathrm{m}$ and $150 \mu \mathrm{m}$. The equipment that was used in carrying out this research work are Grinding Machine model 900 (maker South bay Technology), Sieve, Pulverizing Machine, Monsanto testing Machine for hardness, Izod Impact testing machine, Universal Instron Machine, Model 3369, (maker Instron) for tensile test. As described in American Standard Testing and Measurement (ASTM) method, D638 Test for tensile properties were determined. Five specimens as shown in Table 1 were prepared for the study. A graph of tensile stress versus tensile strain was plotted automatically by the computer. The hardness values of samples were determined according to the provisions in American Society of testing and materials (ASTM E18-79) using the Rockwell hardness tester on "B" scale (Frank Welltest Rockwell Hardness Tester, model 38506) with 1.56mmsteel ball indenter, minor load of $10 \mathrm{~kg}$, major load of $100 \mathrm{~kg}$ and hardness value of $101.2 \mathrm{HRB}$ as the standard block [21, 22].

Table 1. The percentage composition by weight of the composite

\begin{tabular}{|l|l|l|}
\hline S/N & Polyethylene (wt. \%) & Palm kernel waste (wt. \%) \\
\hline 1 & 90 & 5 \\
\hline 2 & 80 & 10 \\
\hline 3 & 70 & 15 \\
\hline 4 & 50 & 20 \\
\hline 5 & Control 100\% & \\
\hline
\end{tabular}

Five different types of composites were produced with the palm kernel fibre and sachet water polyethylene.

\section{Results and Discussion}

Tensile Test. From Fig. 1, tensile strength increases with weight fraction of palm kernel fibre particles in the matrix up to $10 \mathrm{wt} \%$ and then decreases. It clearly indicates that addition of palm kernel fibre particles improves the load bearing capacity of the composites. Similar observations have been reported by [23] for other fiber reinforced polymer composites. The increase in tensile strength with increasing palm kernel fibre particles loading is due to the addition of the particles which increases the stiffness of the composites, which in turn decreases the elongation at break. The highest tensile strength for reinforced with palm kernel fibre particles occurs at $10 \mathrm{wt}$. \% which is $1.96397 \mathrm{MPa}$, while the lowest tensile strength occurs at the control sample with $0 \mathrm{wt} . \%$ with a value of $0.21296 \mathrm{MPa}$.

A graph of tensile stress versus tensile strain was plotted automatically by the computer. The tensile stress versus tensile stain graph was obtained for each composite. 


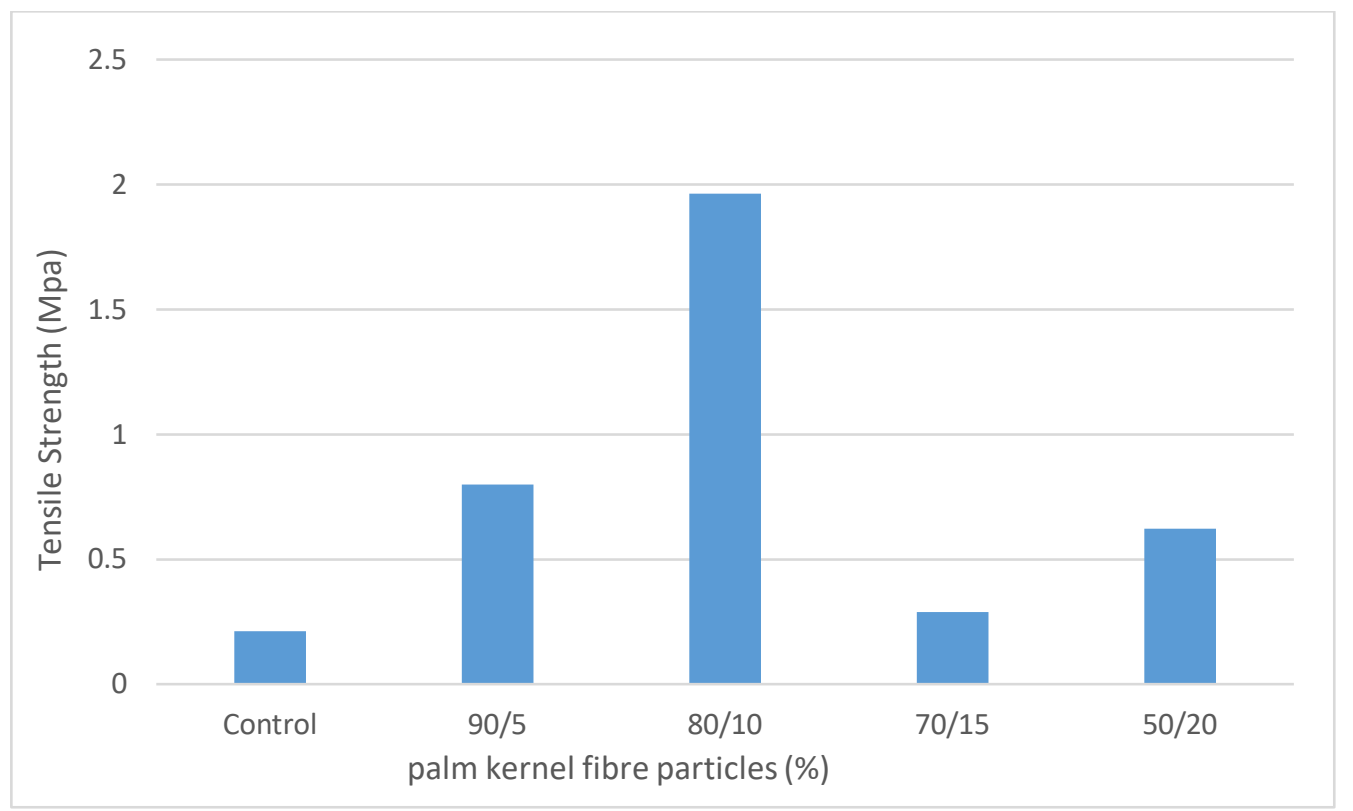

Figure 1. Variation of tensile strength with \% weight of palm kernel fibre particles

The high decreased in tensile strength beyond the optimum point may be attributed to decreasing the interfacial area as the particles content increased, which resulted in worsening the interfacial bonding between the palm kernel fibre particles and polymer matrix. The reduction in tensile strength may also be due to an agglomeration of the palm kernel fibre particles in the polymer matrix which form a domain that looks like a foreign body in the matrix, and these act as obstacles to chains movement and initiate failure under stress. Similar observations have been reported by Aigbodion et al. [24].

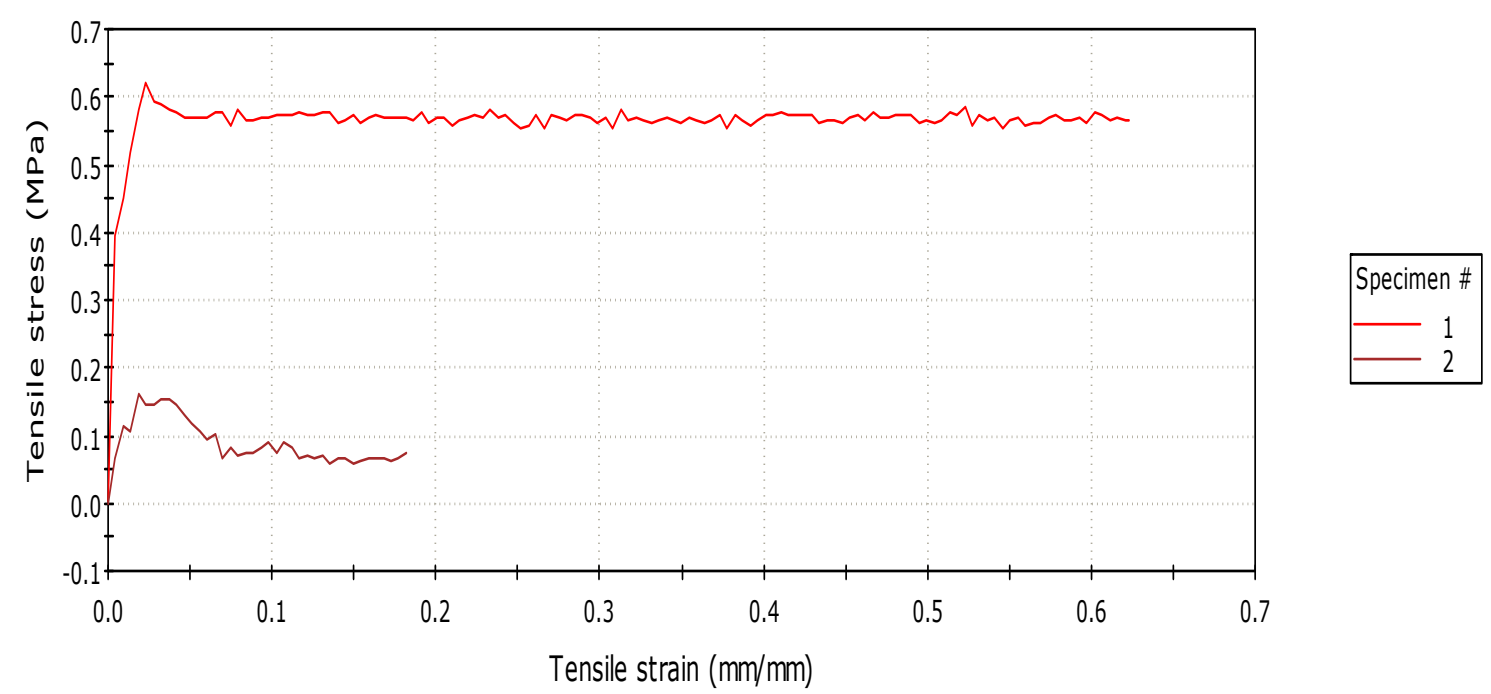

Figure 2. Tensile stress against Tensile stain for the composite material of 50/20 wt. \%

Also from the graph that is generated directly from the machine for tensile test using a computer with respect to load and displacement for Polyethylene -Palm Kernel. The results indicated that Polyethylene - Palm Kernel fibre of 50/20 wt. \% specimen gives tensile strength that is low. The Maximum tensile stress of the Polyethylene-Palm Kernel composite is $0.62247 \mathrm{MPa}$. As such makes the composite not applicable in places or areas of high tensile stress. 
$70 / 15$

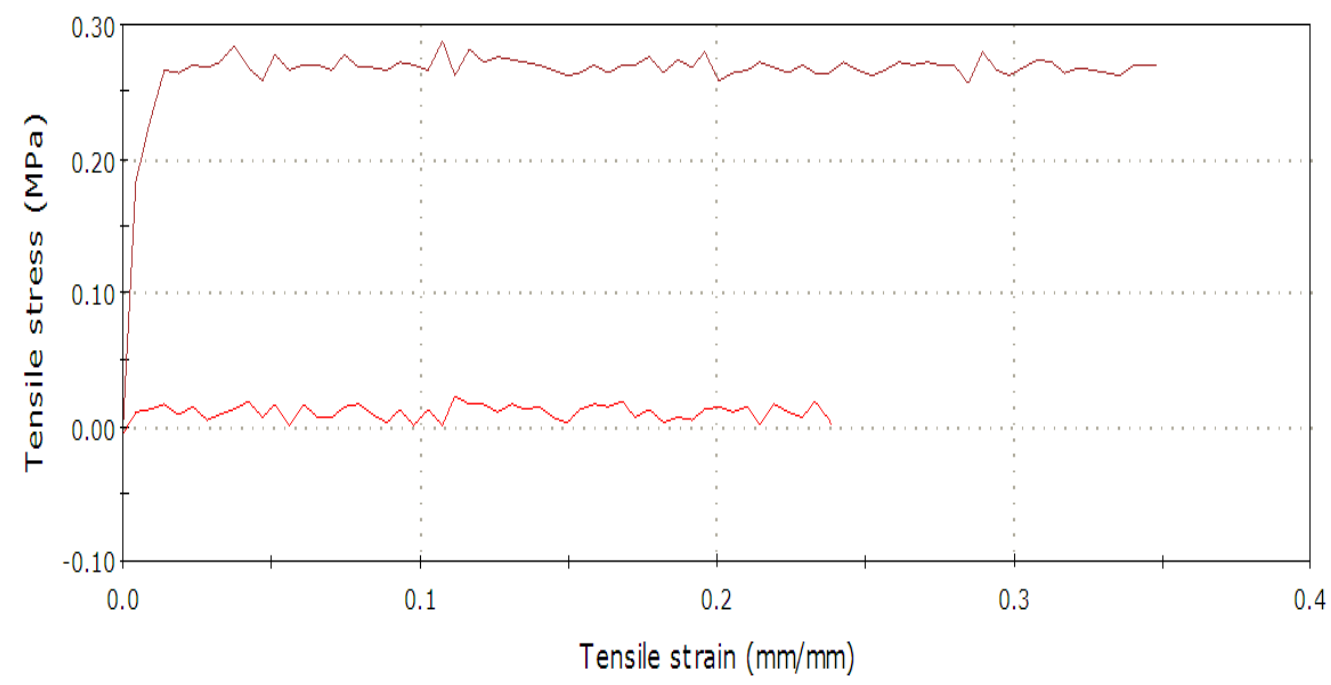

Specimen \#

Figure 3. Tensile stress against Tensile stain of the composite of $70 / 15$ wt. \%

The result of the graph obtained indicated that Polyethylene-Palm Kernel Composite of 70/15 wt. \% specimen gives relatively lower tensile stress as a result of high fibre content addition of more fibre lowers the bearing capacity and the ability of the composite to withstand tensile forces. The Maximum tensile stress of the Polyethylene - Palm kernel Fibre composite is within the range of $0.28771 \mathrm{MPa}$.

$80 / 10$

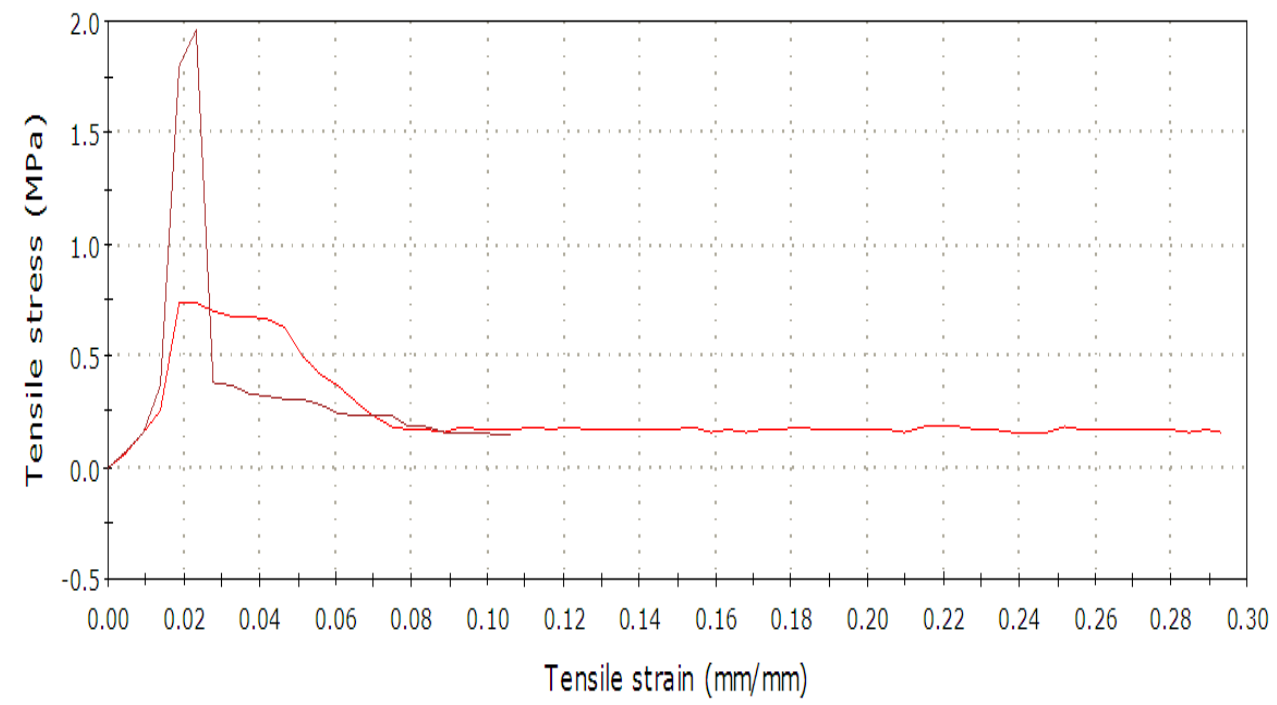

Figure 4. Tensile stress against tensile strain of the composite material of $80 / 10 \mathrm{wt}$. $\%$

From the result of the graph above it indicates that the Polyethylene -Palm Kernel Fibre composite of $80 / 10 \mathrm{wt}$. \% specimen gave the highest tensile strength. The maximum tensile stress of the composite is within the range of $1.96397 \mathrm{MPa}$ before the material fractured. 
$90 / 5$

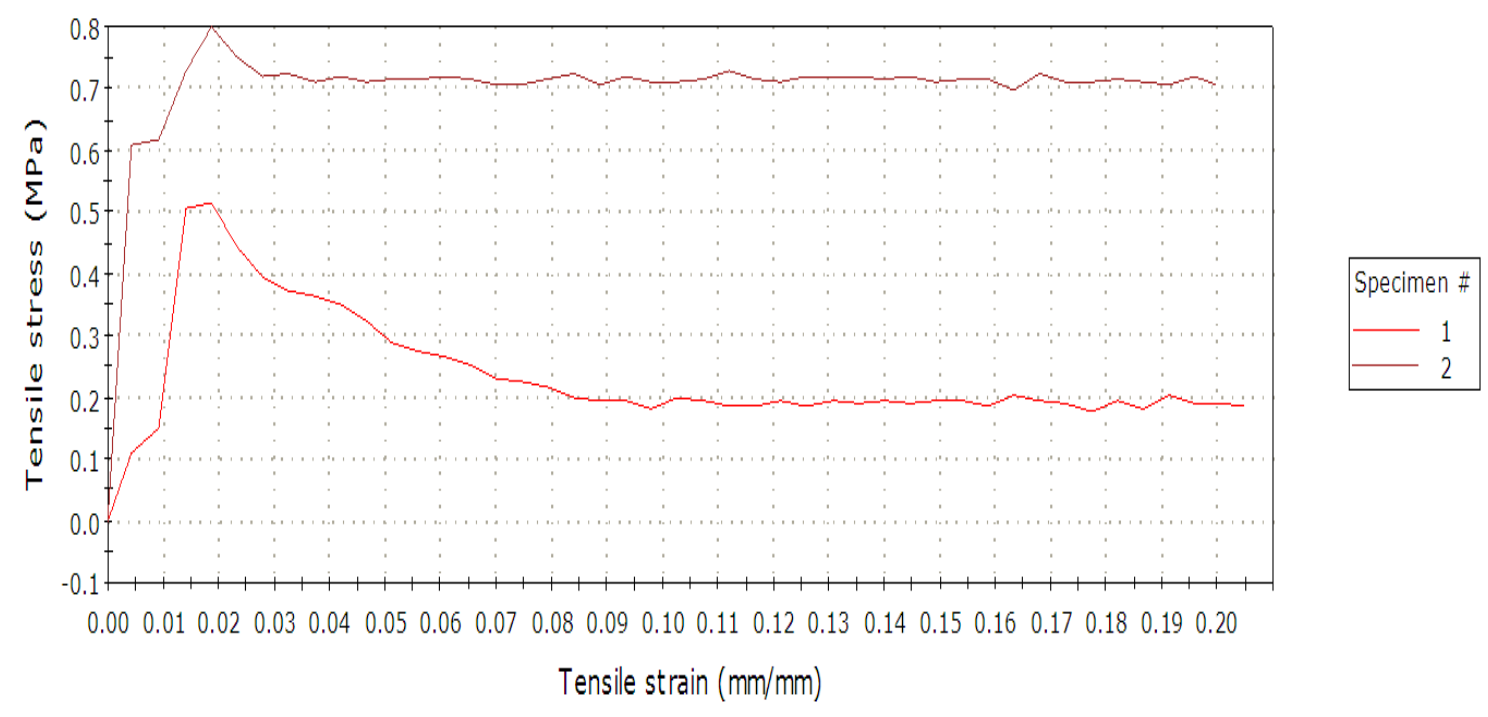

Figure 5. Tensile stress against tensile strain of the composite material of $90 / 5$ wt. \%

The results indicated that the polyethylene - Palm kernel Fibre specimen of 90/5 wt. \% gave the least tensile strength for the reinforced composites.

\section{Control}

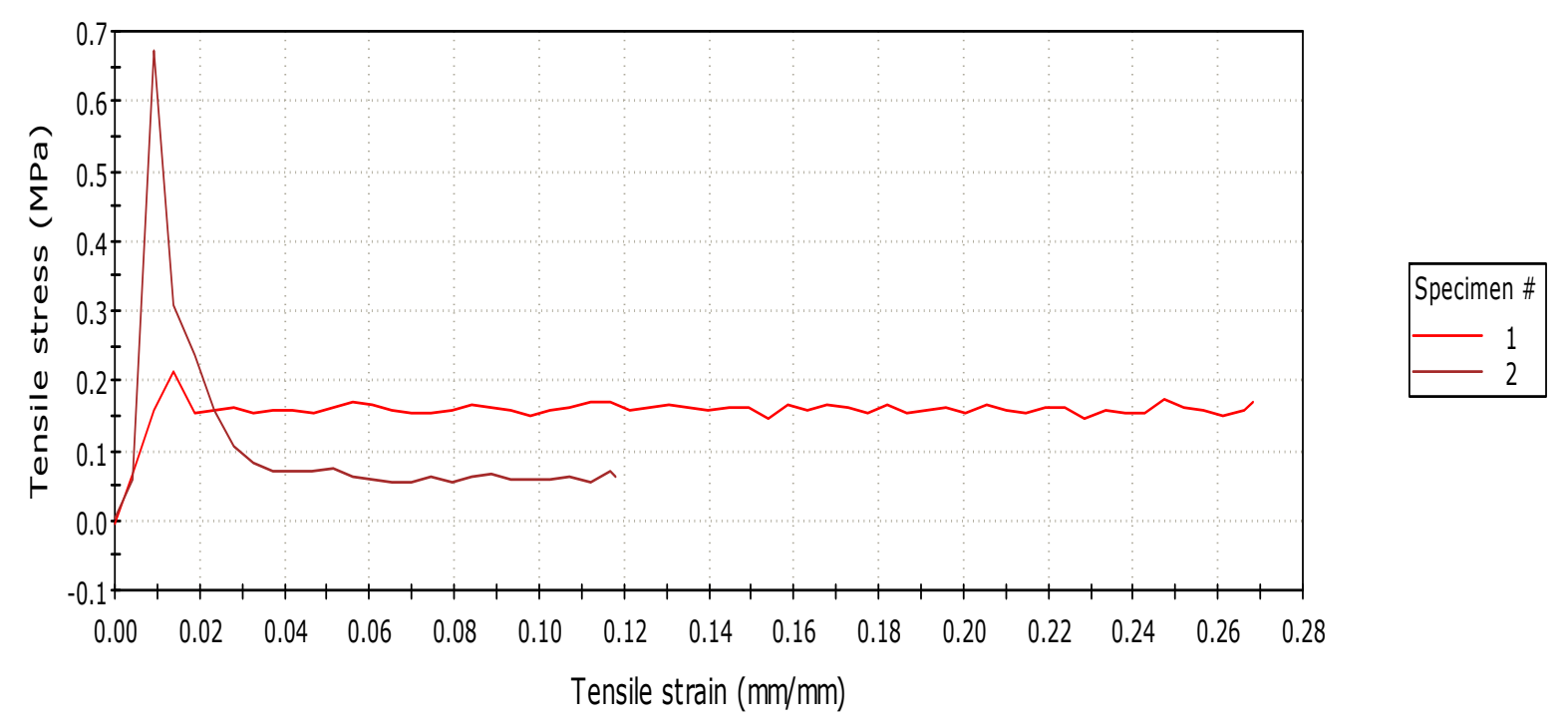

Figure 6. Tensile stress against tensile stain of the control material (Polyethylene)

The sample graph generated directly from the machine for tensile test with respect to load and displacement for the matrix indicated that the unreinforced matrix specimen gives tensile strength that is the lowest. This is as a result of absence of reinforcing material. As can be seen from the graphs and other data analysed, the tensile strength of the composite materials varies with increase in weight fraction of the palm kernel fibre particles in the matrix. This shows that further addition of palm kernel fibre particles above 10 wt. \% lowers the load bearing capacity of the composites. The introduction of the reinforcements lowers the maximum tensile stress obtained from sample 50/20wt. $\%$ to $70 / 15 \mathrm{wt}$. \%. From the research, sample of $80 / 10 \mathrm{wt}$. \% was found to have the best mechanical property among other composites formed. 
Hardness Test. The result of the hardness values with weight percentage of orange peels particles is shown in Fig. 7. The results obtained from the hardness test show that the hardness of the composite material increases with an increase in the percentage of the composite reinforcement. This is due to increase in the percentage of the hard and brittle phase of the ceramics body in the polymer matrix. The hardness number increases from 27.9 HBR obtained from $90 / 5 \mathrm{wt}$. \% sample to $40.5 \mathrm{HBR}$ of the sample $70 / 15$ wt. \% which represents a tremendous increase and then reduced to $21.5 \mathrm{HBR}$ for $50 /$ 20 wt. \% sample. In comparison with the unreinforced polymer matrix, a substantial improvement in hardness values was obtained in the reinforced polymer matrix. The variation in the hardness number of the composite material also agrees with observations made by other researchers $[14,15]$.

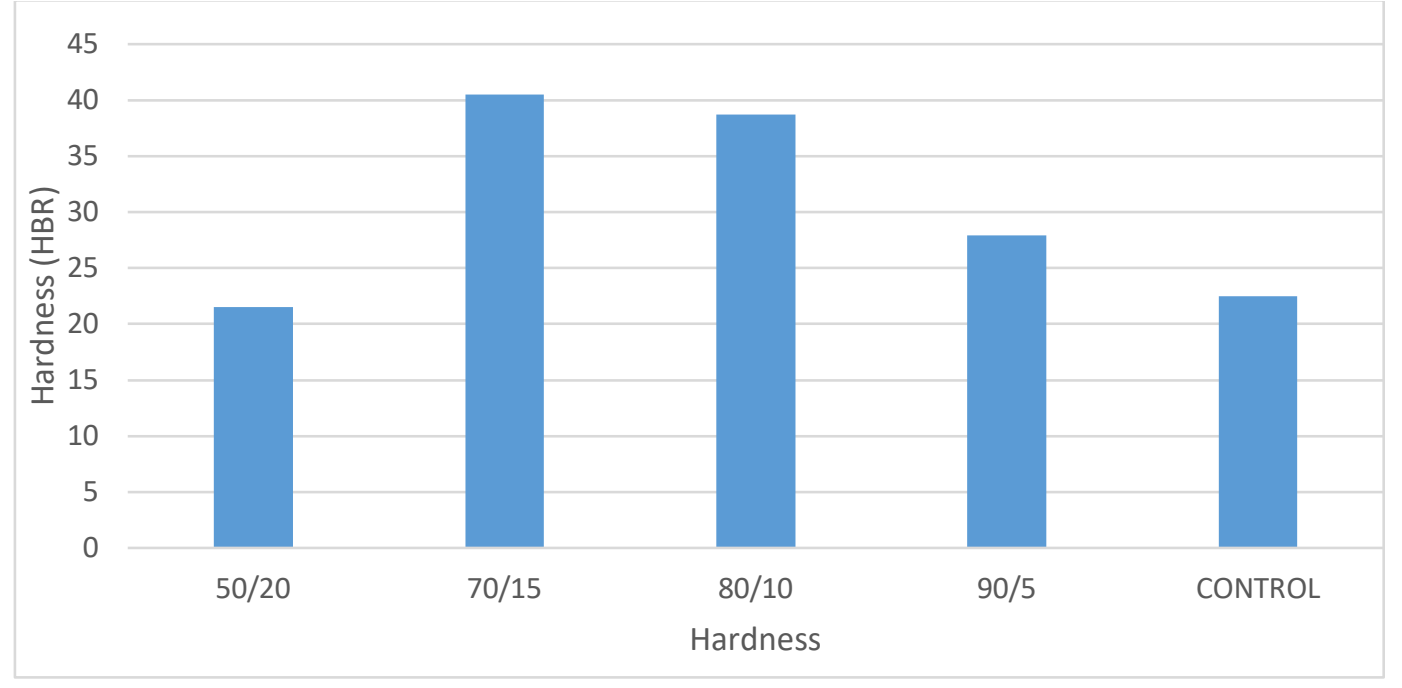

Figure 7. Hardness test of the composite materials

Impact Test. The impact energy absorbed before the material breaks are obtained from the scale on the testing machine using the Izod impact machine. Fig. 8 shows that with an increase in the weight of fibre content the ability of matrix to absorb energy reduces thereby reducing the toughness, so impact strength falls marginally.

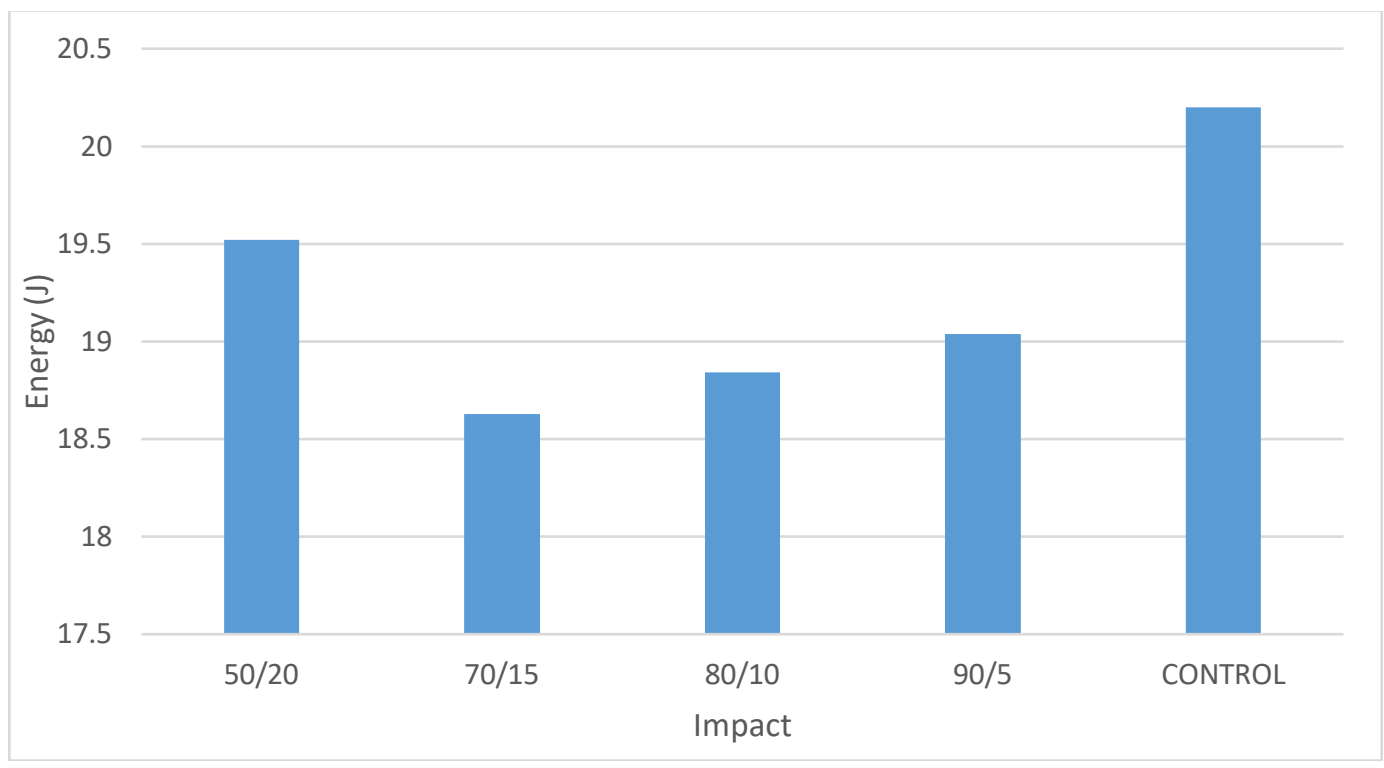

Figure 8. Impact strength of the composite materials

The impact energy of the control sample failed at 20.2 J. Sample with $15 \%$ volume fraction palm kernel fibre in the matrix has the lowest impact energy of $18.63 \mathrm{~J}$ while that obtained from the $20 \%$ sample has highest impact energy. The drop in impact energy is usually associated with the introduction of the particles and this reduces the deformability of the matrix. It was seen that the ability to resist impact force is higher in the unreinforced composite than those reinforced with fibre. 
Morphology. The morphology of palm kernel fibre reinforced polyethylene composite was studied by means of the Accuscope Microscope. The images of composites containing different fraction weight of palm kernel fibre are shown in Fig. 9. It can be seen that micrograph showed various level of adhesion. For the $5 \mathrm{wt}$. \%, it shows there were poor fibre matrix adhesion which is justified by the presence of gaps between both of the fibres and the matrix as shown in Figs. 9. The control unreinforced polyethylene matrix shows no presence of any form of palm kernel fibre particle in. Particles-matrix interface plays an important role in composite properties. A strong particles-matrix interface bond is critical for high mechanical properties of composites [24]. As the palm kernel fibre particle is increased to $20 \mathrm{wt} . \%$, there is some agglomeration of the particles. It displayed a rough morphology with the presence of voids between the filler particles and the polymer matrix, clearly indicating the poor interaction between them. This indicates the presence of reinforcing particles grossly rejected by the polymer. From Figs. 9c with palm kernel fibre of 15 wt. \%, the presence of more polyethylene reduced the voids sizes and turned the surface more homogeneous confirming its effect on promoting adhesion in the interfacial region. The Micrograph of reinforced composite of 10 wt. \% palm kernel fibre shows the presence of the reinforcing composite sparsely rejected by the polymer. It can be observed that the $10 \mathrm{wt}$. \% samples have a smoother adhesion compared to the 5 wt. \%. samples in Fig. 9e. It is very clear that the filler weight increases the effective surface area available for wetting by the polymer matrix.

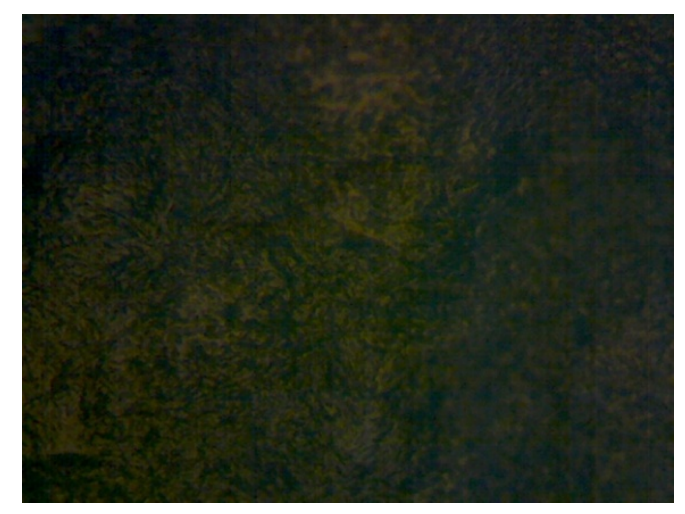

(a)

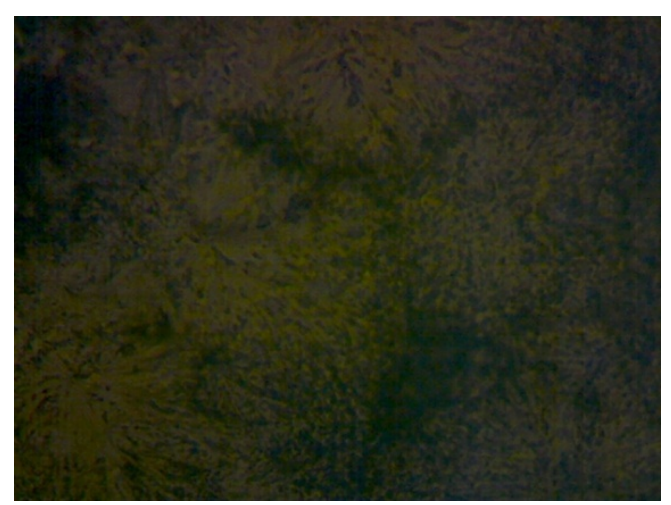

(c)

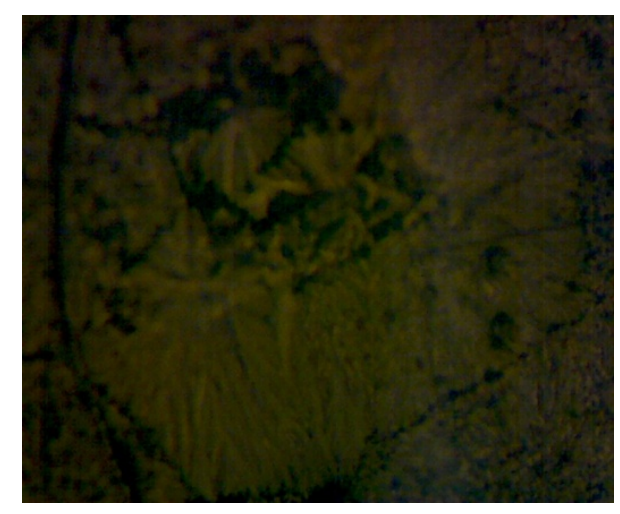

(b)

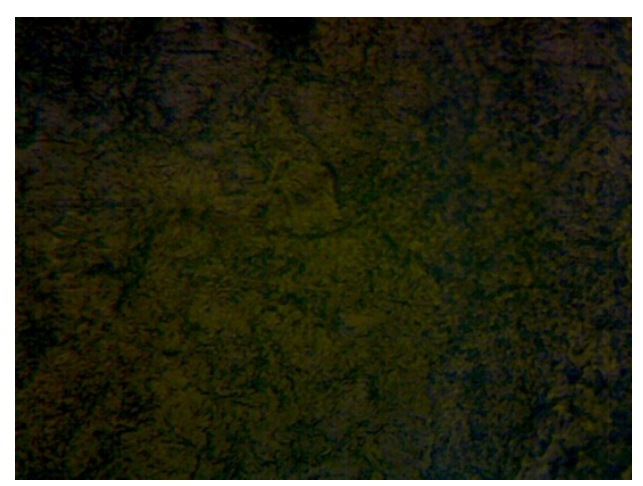

(d) 


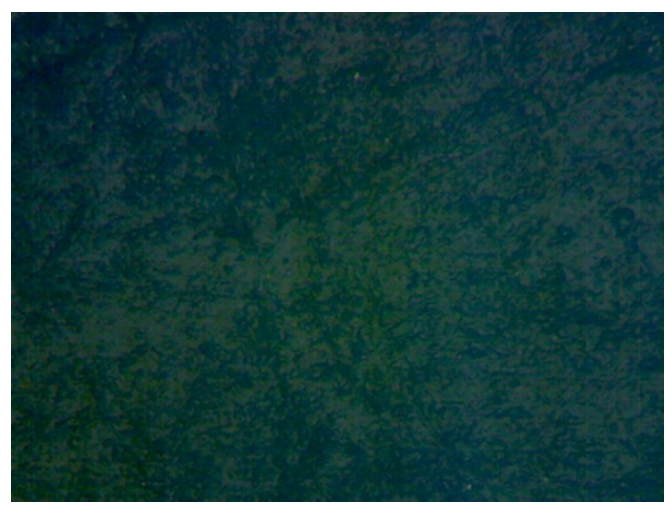

(e)

Figure 9. Micrographs of composites a) without fibre; b) with 20wt. \% fibre; c) with 15 wt. \% fibre; d) with 10 wt. \% fibre; e) with 5 wt. \% fibre

\section{Conclusions}

In this present work, successful investigation of the mechanical properties of palm kernel fibre reinforced with a waste water sachet material was carried out. From the results obtained, the hardness value of the palm kernel fibre composites increases which is attributed to the increase in the ratio of palm kernel fibre of each sample. The tensile strengths slightly decreased, however they were improved in the $10 \mathrm{wt} . \%$. This shows that palm kernel fibre has good bonding between the matrixes at a good proportion. The impact test shows that the composite with the 90/10 wt. \% of fibre and matrix has a significant increase in impact strength also the control has a good impact strength. The $15 \%$ reinforced composite was found to be good results compared to the unmodified. The composite with the maximum tensile property and a good hardness property can be used for both mechanical equipment and consumables.

\section{References}

[1] A. Gadgi, E. Derby, Providing safe drinking water to 1.2 billion unserved people (No. LBNL52374). Lawrence Berkeley National Lab. (LBNL), Berkeley, CA (United States).

[2] M.B Adetunji, B.M. Ilias, Externally Effects of sachet water consumption and the choice of policy instruments in Nigeria: Evidence from Kwara State: Journal of Economics. 1(2) (2010) 113-131.

[3] L. Egwari, O. Aboaba, Environmental impact on the bacteriological quality of domestic water supplies in Lagos, Nigeria.Rev. Saude Publica. 36(4) (2002) 513-520.

[4] T. Ademiluyi, T.A. Adebayo, Fuel gases from hydrolysis of waste polyethylene sachet. J. Appl. Sci. Environ. Manag. 11(2) (2007) 21-26.

[5] H. Salmah, A. Romisuhani, H. Akmal, Properties of low - density polyethylene/palm kernels hell composites: Effect of polyethylene co-acrylic acid, Thermoplastic Composite Materials. 26(1) (2013) 3-15.

[6] P.J. Herrera-Franco, A. Valadez-Gonza'lez, A study of the mechanical properties of short naturalfiber reinforced composites, Composites Part B: Engineering. 36(8) (2005) 597-608.

[7] R.M. Mizanur, A. Mubarak, B. Khan, Surface treatment of coir (Cocosnucifera) fibers and its influence on the fiber sphysico- mechanical properties, Composites Science and Technology. 67 (2007) 2369-2376.

[8] I. Samotu et al., Waste to wealth: A case study of empty water sachet conversion into composite material for automobile application. World Journal of Engineering. 11 (2014) 199-208. 
[9] G. Amoako et al., Some Mechanical Properties of Coconut Fiber Reinforced Polyethylene Composite to Control Environmental Waste in Ghana. Energy and Environment Research. 8 (2018) 1 .

[10] I. Samotu et al., The effects of carbonized palm kernel shell (CPKS) loading on the mechanical properties of recycled low density polythene matrix composite material. In Conference of Nigerian Metallurgical Society, Nigeria, Volume 28, 2012.

[11] M.S. Huda et al., The effect of silane treated-and untreated-talc on the mechanical and physicomechanical properties of poly(lactic acid)/newspaper fibers/talc hybrid composites. Composites: Part B. 38 (2007) 367-379.

[12] G. Clemons, A. R. Sanadi, Instrumented impact testing of kenaf fiber reinforced polypropylene composites: effects of temperature and composition, Journal of Reinforced Plastics and Composites, 26(15) (2007) 1587-1602.

[13] R.P Singh et al., Management of biomass residues generated from palm oil mill: Vermicomposting a sustainable option. Resources, Conservation and Recycling. 55(4) (2011) 423434.

[14] N. Dhib, R. Al-Nidawy, Modelling of free Radical Polymerisation of Ethylene Using Dysfunctional initiators, Chem. Eng. Sci. 57 (2002) 2735-2746.

[15] M.F. Ashby, Composites: Resins, Fillers, Reinforcements Philosophical Transactions of the Royal Society of London, A322: 393. Business Communications Co, Inc. (1987)

[16] A.K. Bledzki. J. Gassan, Composites reinforced with cellulose based fibres. Progress in Polymer Science. 199(24) (1999) 221-274.

[17] G. Amoako et al., Some Mechanical Properties of Coconut Fiber Reinforced Polyethylene Composite to Control Environmental Waste in Ghana, Energy and Environment Research. 8(1) (2018).

[18] I.A. Samotu et al., Waste to Wealth; A case study of empty water sachet conversion into composite material for automobile application, Engineering. 1(3) (2014) 199-208.

[19] M.A. Abdullah, M.S Nazir, B.A.Wahojedi, Development of value-added Biomaterials from oil palm Agro-wastes, 2nd International Conference on Biotechnology and Food Science. (2011) 3235.

[20] B.A. Acha, N.E. Marcovich, M.M. Reboredo, Physical and mechanical characterization of jute fabric composites. Applied Polymer Science. 98 (2005) 639-650.

[21] O. Obiukwu, I. Opara, H. Udeani, Study on the Mechanical Properties of Palm Kernel Fibre Reinforced Epoxy and Poly-Vinyl Alcohol (PVA) Composite Material, International Journal of Engineering and Technologies. 7 (2016) 68-77.

[22] I.O. Eze et al., Mechanical Properties of Pineapple Leaf Powder Filled High Density Polyethylene, International Journal of Engineering and Technologies. 9 (2016) 13-19.

[23] American Society for Testing and Materials (ASTM) 2000. ASTM D 638-99-2000 and 790-992000. ASTM Committee on Standards.

[24] V.S. Aigbodion et al., Development of High-Density Polyethylene/Orange Peels Particulate BioComposite, Gazi University Journal of Science. 26(1) (2013) 107-117. 